\title{
DEM GENERATION BASED ON COMMERCIAL UAV
}

PHOTOGRAMMETRY DATA

\author{
Mikhail Aleshin $^{1}$, Larisa Gavrilova ${ }^{2}$, Igor Goryainov ${ }^{3}$, Andrey Melnikov ${ }^{1}$ \\ ${ }^{1}$ Peoples' Friendship University of Russia, Russia; \\ ${ }^{2}$ State University of Land Use Planning, Russia; \\ ${ }^{3}$ Moscow State University of Geodesy and Cartography, Russia \\ m.aleshin.net@mail.ru,wernjer@gmail.com, \\ igorgoryainov@yandex.ru, acornum@mail.ru
}

\begin{abstract}
Unmanned aerial vehicles (UAVs) are used more and more widely in various fields of activity and production. Industries using UAV images include agriculture and land use planning. From the images from the $\mathrm{UAV}$, it is possible to generate digital elevation models (DEM) and digital terrain models (DTM) in a stereophotogrammetric manner, which can be used later for design work. At the same time, there is no need to use expensive specialized UAVs, since budget models of the domestic segment also allow to generate digital terrain models of high accuracy. So, for example, using the PHANTOM 4 model and using certain techniques, it is possible to generate DEM with an error of heights of 5-10 $\mathrm{mm}$. However, such results were obtained due to the creation of almost ideal conditions for aerial survey. The authors of this work were tasked with investigating the possibility of DEM generation of a required accuracy with various options for the location of ground reference points, various parameters of aerial survey provided that photogrammetric processing of images will be carried out in the software Agisoft PhotoScan. To achieve these goals, an object for testing was selected, on which a network of reference and control points was created using a total station. According to the previously calculated parameters, aerial survey was carried out with a PHANTOM 4 UAV. Photogrammetric processing of aerial photographs was carried out in the software Agisoft PhotoScan. The accuracy of digital elevation models was assessed using the least squares method. According to the results of the calculations, the corresponding conclusions are made.
\end{abstract}

Keywords: digital elevation model (DEM), unmanned aerial vehicle (UAV), ground reference points, RMSE (root mean square error).

\section{Introduction}

The main objective of this work is to study the possibility of high-precision DEM generation by the stereophotogrammetric method from images from UAVs. As known, the accuracy of DEM generation by the stereophotogrammetric method depends on the accuracy of determining the interior and exterior orientation parameters of the images and the degree to which physical factors are taken into account (lens distortion, atmospheric refraction, etc.).

The task is to assess the influence of the location of the control points on the accuracy of calculating the exterior orientation parameters and, as a consequence, on the accuracy of the DEM. At the same time, various options for the location of ground control points are considered - along the perimeter of the processing zone and locally.

The software Agisoft PhotoScan used in the work allows self-calibration of images and thus considers the lens distortion. This is an important fact, since the non-metric cameras that are included with commercial UAVs have significant distortion.

The study of the possibility of using a stereophotogrammetric method for high-precision DEM generation, as well as locally located reference points when such DEM generation, is important in cases of work in hard-to-reach areas. The use of traditional land-based geodetic methods for DEM generation in difficult of approach areas in most cases becomes impossible.

In addition, the density of the DEM pickets generated by the stereophotogrammetric method is significantly higher than by the geodetic method.

The study took place in four stages:

1. Preparatory phase;

2. Aerial survey;

3. DEM generation in a stereo-photogrammetric manner in the software Agisoft PhotoScan;

4. Evaluation of the accuracy of the generated DEMs 


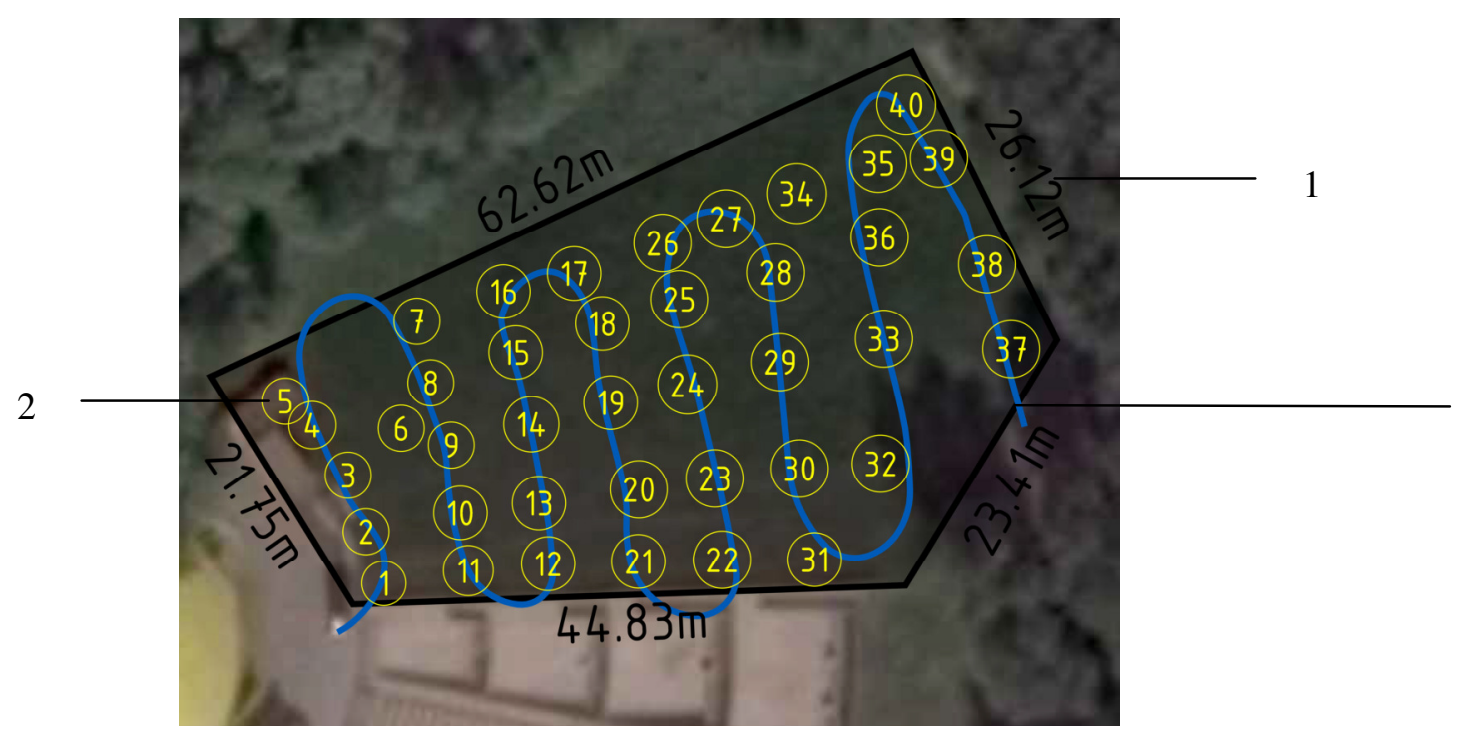

Fig. 1. Object of study: 1 - sizes of the object; 2 - ground control points; 3 - flight strips

\section{Materials and methods}

\section{The first part of the preparatory phase}

To generate a DEM of a required accuracy by the stereo-photogrammetric method, the following parameters of aerial survey were calculated: the flying height above ground and stereo overlap. The calculation of these parameters in this work was carried out in a simplified way according to the formula for calculating the expected error of the heights of the terrain points from measurements on a stereopair (1).

$$
m_{Z}=\frac{H m_{p}}{b},
$$

where $m_{Z}-$ RMSE of the heights, $m$;

$H$ - flying height, m;

$m_{p}-$ RMSE of parallax difference, pix;

$b$ - image base, pix.

The value of $m_{p}$ during automated processing of aerial photos is equal to the error in the reprojection of tie points and was determined as a result of a test survey and subsequent photogrammetric processing of the survey results in the software Agisoft Photoscan. Also, as a result of these actions, the values of the principal distance and pixel size of the camera's matrix were determined (Table 1).

\section{Camera calibration data}

Table 1

\begin{tabular}{|c|c|}
\hline Position & Description \\
\hline Camera, model & FC330 $(3.61 \mathrm{~mm})$ \\
\hline Resolution & $4000 \times 3000 \mathrm{pix}$ \\
\hline Principal Distance & $3.61 \mathrm{~mm}$ \\
\hline Pixel Size & $1.56 \times 1.56 \mu \mathrm{m}$ \\
\hline Reprojection Error & $0.556 \mathrm{pix}$ \\
\hline
\end{tabular}

The RMSE of the heights is taken equal to $0.02 \mathrm{~m}$. Also, to reduce the effect of distortion, the stereo overlap was adopted $80 \%$. The amount of stereo overlap determines the image base. And since the technical capabilities of the Phantom 4 UAV allow tracking only along the short side of the image, the image base in our case was 600 pix.

Thus, according to formula 2 flying height was calculated. Based on our data, the estimated flying height was $24 \mathrm{~m}$. 


$$
H=\frac{m_{Z} b}{m_{p}},
$$

\section{The second part of the preparatory phase}

To assess the accuracy of the DEM generated by the stereo-photogrammetric method, a reference DEM is required. In our case, the network of ground control points acted as the reference DEM. Ground network was created using the Leica TS 09 Plus Total Station. The coordinate system of the ground network was conditional. The $\mathrm{X}$ axis is oriented northward along the magnetic azimuth. The mutual accuracy of the ground control points was $4 \mathrm{~mm}$. The black crosses printed on A4-sized paper were used as ground control points, the thickness of the lines was $40 \mathrm{~mm}$, and the spatial resolution at the selected flying height was $10 \mathrm{~mm}$ per pixel. The configuration of the ground control points is presented in Fig. 1.

In order to provide the calculated flying height and stereo overlap as accurately as possible, it is necessary to compose correctly a flight task. The flight task was created in the DJI GO program by setting the flight strip, flying height and the exposure interval, which was calculated based on the aerial photo base and a fixed UAV speed. The scheme of the flight strips is shown in Fig. 1.Aerial survey was carried out in clear weather in the absence of wind. According to the results of the aerial survey, 39 photos of the object were obtained. Photogrammetric processing of images was carried out in the software Agisoft Photoscan. All metadata were deleted from the photos, including the navigational coordinates of the camera stations, since the processing was carried out exclusively with the use of the ground control points. The coordinates of all ground control points were imported into the project as a text file. Processing was carried out in two versions.

In the first version, ground points $1 ; 5 ; 37 ; 40$ were used as reference points, located in the corners of the tested area. All the other ground points were used as control points. The so-called masks were also loaded into the project, which limit the zones of the location of tie points by the working areas of the images. General properties of the project are presented in Table 2.

Table 2

\section{General project properties - Version 1}

\begin{tabular}{|c|c|}
\hline Position & Description \\
\hline Number of images & 39 \\
\hline Flying height & $23.1 \mathrm{~m}$ \\
\hline Spatial resolution & $8.47 \mathrm{~mm}$ per pix \\
\hline Coverage area & $4.09 \mathrm{e}+03 \mathrm{~m}^{2}$ \\
\hline Camera stations & 39 \\
\hline Tie points & 30816 \\
\hline Projections & 157109 \\
\hline Reprojection error & $0.609 \mathrm{pix}$ \\
\hline
\end{tabular}

The accuracy was estimated using the least squares method according to the deviations of the equalized values of the coordinates of the control and reference points from the original values of the coordinates of the points. The results of the accuracy assessment of the first version are given in Table 3 and Fig. 2.

Table 3

Assessment of accuracy by reference points - Version 1

\begin{tabular}{|c|c|c|c|c|c|}
\hline Label & $\boldsymbol{X}$ error, $\mathbf{~ m m}$ & $\boldsymbol{Y}$ error, $\mathbf{~ m m}$ & $\boldsymbol{Z}$ error, $\mathbf{~ m m}$ & Total error, $\mathbf{~ m m}$ & Image error, pix \\
\hline 1 & -0.7 & -2.3 & -5.3 & 5.8 & 0.323 \\
\hline 5 & 7.4 & -2.3 & -1.4 & 7.9 & 0.257 \\
\hline 37 & -3.9 & -1.2 & 5.3 & 6.7 & 0.255 \\
\hline 40 & -0.5 & -2.4 & 2.0 & 3.2 & 0.538 \\
\hline Total & 4.2 & 2.1 & 4.0 & 6.1 & 0.328 \\
\hline
\end{tabular}

As it can be seen from the results of the accuracy assessment, the RMSE of the coordinates of the reference points was $6.1 \mathrm{~mm}$, the total RMSE of the coordinates of the control points was $19.1 \mathrm{~mm}$. 
Such accuracy can be considered excessive for the most land use planning works. Based on this, it makes sense to consider the possibility of obtaining a less accurate result with other parameters of aerial survey that are used in the second version.

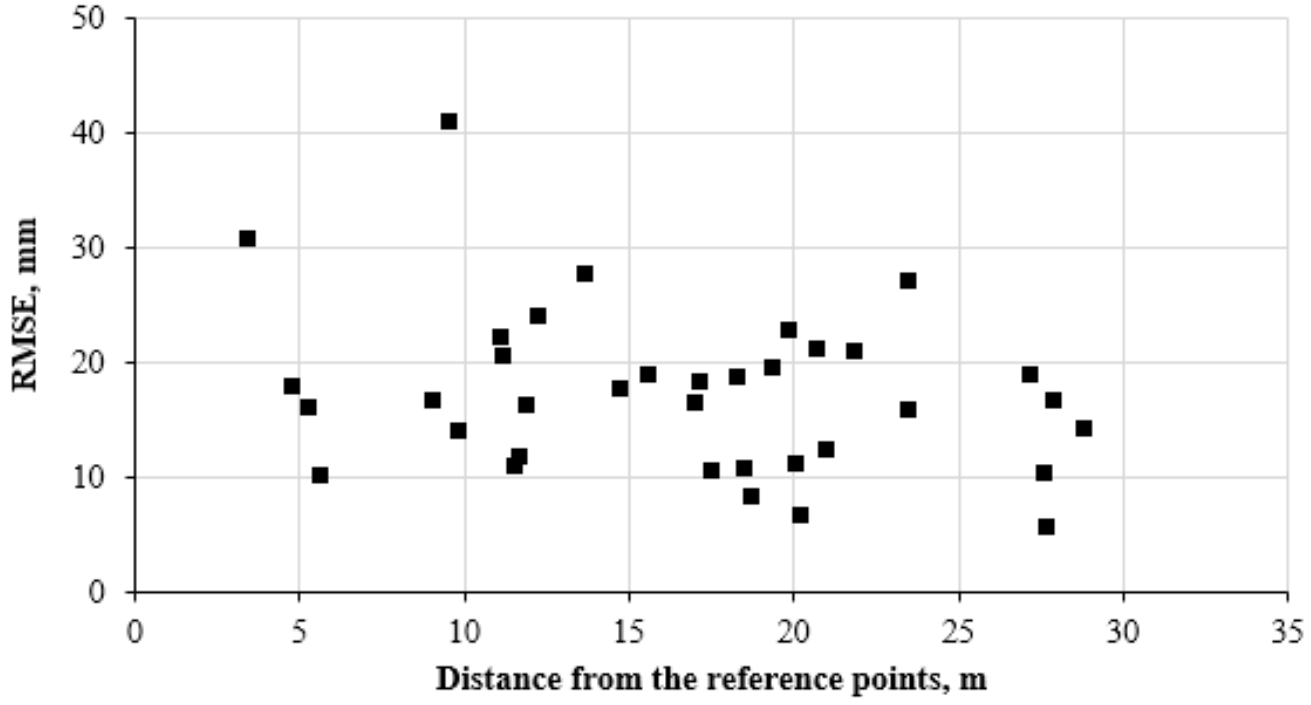

Fig. 2. Dependence of the RMSE of the DEM points on the distance from the reference points - Version 1

In the second version, the smallest possible number of ground control points was chosen -3 , their location was in the center of the site, the stereo overlap of the images was $60 \%$ due to the removal of every second image from the processing. The ground control points $19 ; 20 ; 23$ were chosen as reference points. The results of the accuracy assessment for the second version are given in Table 4 and Fig. 3, the position of the reference and control points and error estimation are presented in Fig. 4.

Table 4

Assessment of accuracy by reference points - Version 2

\begin{tabular}{|c|c|c|c|c|c|}
\hline Label & $\boldsymbol{X}$ error, $\mathbf{~ m m}$ & $\boldsymbol{Y}$ error, $\mathbf{~ m m}$ & $\boldsymbol{Z}$ error, $\mathbf{~ m m}$ & Total error, $\mathbf{~ m m}$ & Image error, pix \\
\hline 19 & 0.2 & 0.1 & -0.2 & 0.3 & 0.420 \\
\hline 20 & 0.6 & -0.3 & -0.1 & 0.7 & 0.269 \\
\hline 23 & -0.2 & -0.4 & 0.1 & 0.4 & 0.316 \\
\hline Total & 0.4 & 0.3 & 0.2 & 0.5 & 0.352 \\
\hline
\end{tabular}

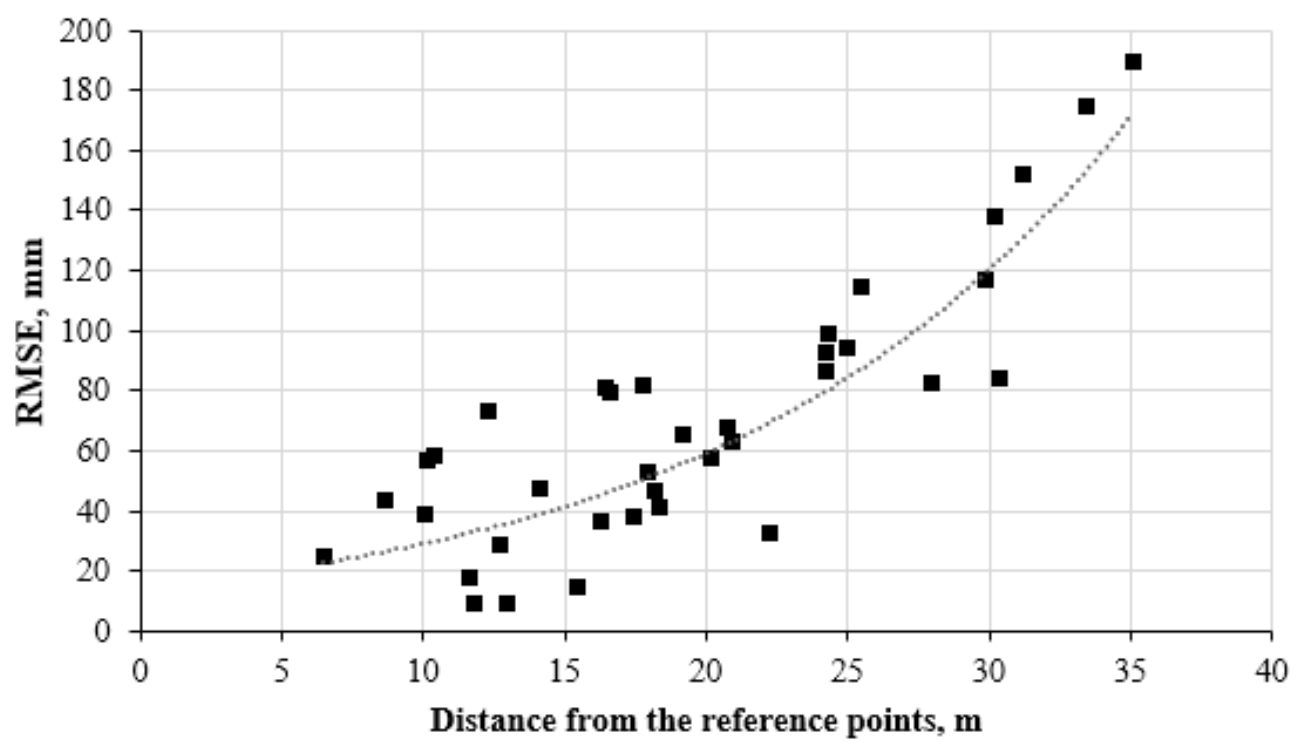

Fig. 3. Dependence of the RMSE of the DEM points on the distance from the reference points - Version 2 


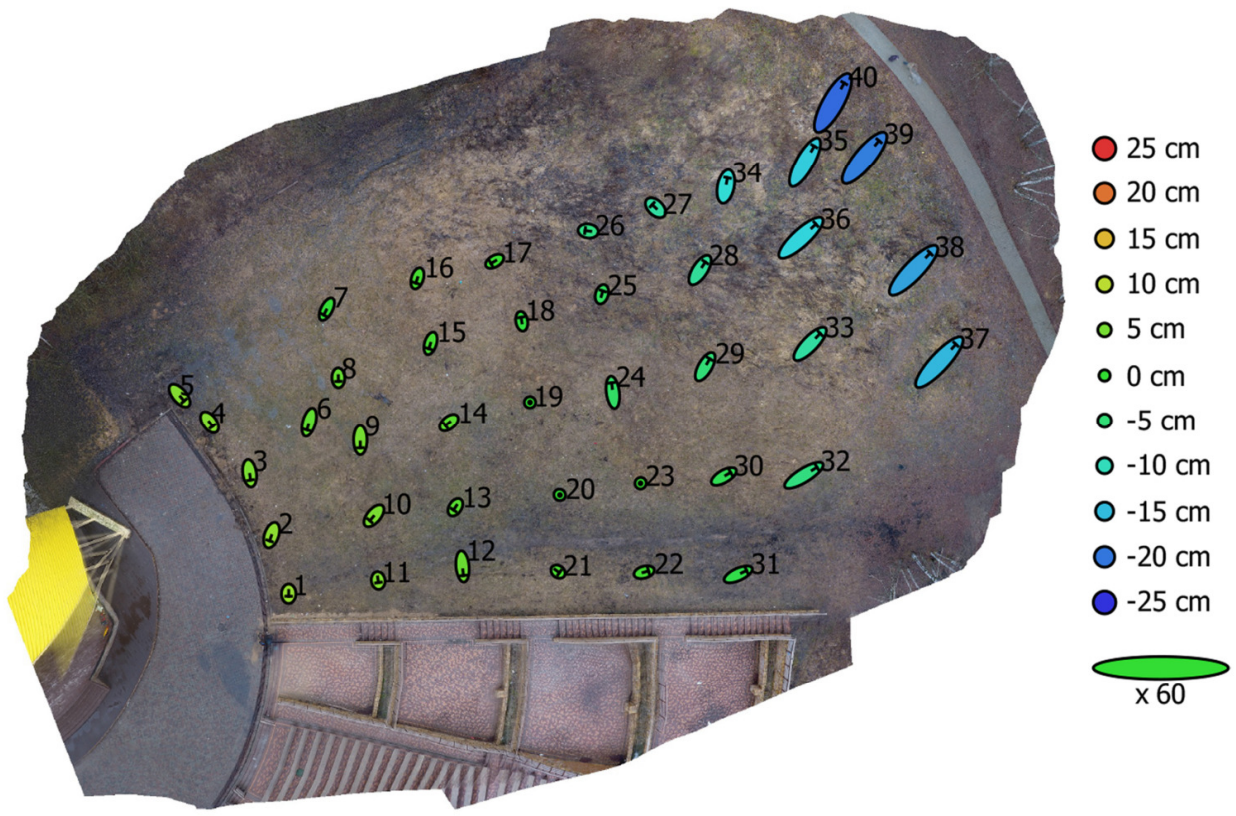

--Reference points T -Control points

$20 \mathrm{~m}$

Fig. 4. GCP locations and error estimates: Version $2-Z$ error is represented by ellipse colour; $\mathrm{X}, \mathrm{Y}$ errors are represented by ellipse shape

As it can be seen from the results of the accuracy assessment, the RMSE of the coordinates of the reference points was $0.5 \mathrm{~mm}$, the total RMSE of the coordinates of the control points was $83.7 \mathrm{~mm}$. It can be seen from Fig. 3 and Fig. 4 that the magnitude of the error in plan and in height increases markedly with the distance of the control points from the zone of the reference points. Nevertheless, even such a result can be considered satisfactory. The generated DEM also has a rather high density of 30.9 points $\cdot \mathrm{m}^{-2}$. The visualized DEM is shown in Fig. 5. Such a model can be exported to many formats and used, in particular, in CAD programs for design.

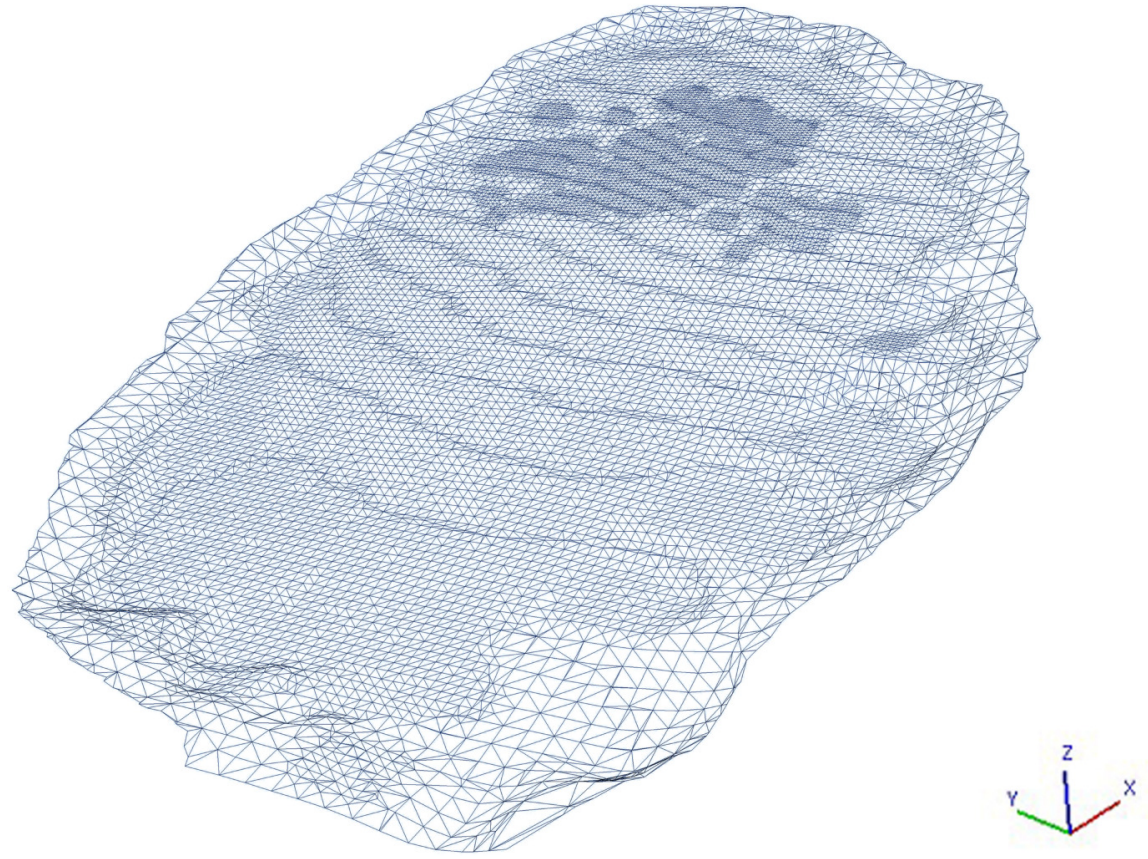

Fig. 5. Visual representation of the DEM 


\section{Results and discussion}

The research suggests that it is possible to generate high-precision DEM using stereophotogrammetric methods from UAV images.

The accuracy of coordinates of DEM points $(0.02 \mathrm{~m})$ by the stereophotogrammetric method is achieved in the case of the location of reference points along the perimeter of the processing zone. It should be borne in mind that the conclusion refers to the case of using images obtained with the FC330 camera $(3.61 \mathrm{~mm})$ in a scale 1: 6650 .

In the case of a local location of the reference points, the specified accuracy of coordinates of DEM points $(0.02 \mathrm{~m})$ is achieved within a radius of $7 \mathrm{~m}$ from the center of gravity of the triangle formed by the reference points.

The graphs of the dependence of the RMSE of the DEM points on the distance from the reference points show that within a radius of $20 \mathrm{~m}$ the height errors do not exceed $0.08 \mathrm{~m}$. Within a radius of 35 $\mathrm{m}$ from the reference points, the errors in the heights of the DEM do not exceed $0.17 \mathrm{~m}$, which corresponds to the necessary height accuracy at the construction of a topographic plan on a scale of 1 : 500 with a contour interval $0.5 \mathrm{~m}$. Plans with such characteristics are used for projects of anti-erosion organization of the territory.

In addition, a comparison of the graphs of the dependence of the errors of DEM heights on the layout of the reference points allows us to conclude that when the reference points are located along the perimeter of the processing zone, a uniform distribution of height errors $(0.01-0.04 \mathrm{~m})$ over the field of the work area is observed.

With the local location of the reference points, the error in determining the DEM heights depends on the distance of the points from the reference points. Presumably, the dependence can be expressed by a power function.

\section{Conclusions}

1. The use of images obtained from non-specialized UAVs allows to generate DEM of specified accuracy by the stereo-photogrammetric method. The necessary conditions for DEM generation of a high precision are:

2. The presence of a ground reference network, the coordinates of the points of which are determined with an error not exceeding the spatial resolution.

- Carrying out aerial survey strictly according to previously calculated parameters.

- Compliance with aerial survey processing techniques in the software Agisof Photoscan.

- Subject to all the above conditions, the accuracy of the generated DEM is not inferior to the accuracy of the DEM generated by the traditional ground-based survey method, and its density is much higher than that of the traditional method

3. The use of DEMs generated from UAV images to accompany land use planning can save time and achieve high accuracy.

4. It seems advisable to continue the study of the accuracy of DEM generation by the photogrammetric method from UAV images in order to formulate specific recommendations for various conditions of aerial survey and photogrammetric processing.

\section{References}

[1] Martínez-Carricondo P., Agüera-Vega F., Carvajal-Ramírez F. etc. Assessment of UAVphotogrammetric mapping accuracy based on variation of ground control points. International Journal of Applied Earth Observation and Geoinformation, vol. 72, 2018, pp. 1-10.

[2] Agüera-Vega F., Carvajal-Ramírez F., Martínez-Carricondo P. Assessment of photogrammetric mapping accuracy based on variation ground control points number using unmanned aerial vehicle. Journal of the International Measurement Confederation, vol. 98, 2017, pp. 221-227.

[3] Aleshin M., Gavrilova L., Melnikov A. Use of unmanned aerial vehicles on example of Phantom 4 (standard) for creating digital terrain models. Proceedings of 19th International Scientific Conference "Engineering for Rural Development", May 22-24, 2019, Jelgava, Latvia, pp. 16861692. 
[4] James M., Robson S., d'Oleire-Oltmanns S. etc. Optimising UAV topographic surveys processed with structure-from-motion: Ground control quality, quantity and bundle adjustment. Geomorphology, vol. 280, 2017, pp. 51-66.

[5] Rusnák M., Sládek J., Kidová A. etc. Template for high-resolution river landscape mapping using UAV technology. Measurement, vol. 115, 2018, pp. 139-151.

[6] Boon M., Greenfield R., Tesfamichael S. Unmanned Aerial Vehicle (UAV) photogrammetry produces accurate high-resolution orthophotos, point clouds and surface models for mapping wetlands. South African Journal of Geomatics, vol. 5 No. 2, 2016, pp. 186- 200.

[7] Hugenholtz C., Brown O., Walker J. etc. Spatial accuracy of UAV-derived orthoimagery and topography: Comparing photogrammetric models processed with direct geo-referencing and ground control points. Geomatica, vol. 70, 2016, pp. 21-30.

[8] Yang C., Tsai M., Kang S. etc. UAV path planning method for digital terrain model reconstruction - A debris fan example. Automation in Construction, vol. 93, 2018, pp. 214-230.

[9] Long N., Millescamps B., Pouget F. Accuracy assessment of coastal topography derived from uav images. Proceedings of International Archives of the Photogrammetry, Remote Sensing and Spatial Information Sciences, July 12-19, 2016, Prague, Czech Republic, vol. XLI-B1, pp. 11271134. Evaluating the Potential of PPK Direct Georeferencing for UAV-SfM Photogrammetry and Precise Topographic Mapping. Earth Surface Dynamics Discussions.

[10]Zhang H., Aldana-Jague E., Clapuyt F. Evaluating the Potential of PPK Direct Georeferencing for UAV-SfM Photogrammetry and Precise Topographic Mapping. Earth Surface Dynamics Discussions, vol. 7, issue 3, 2019, pp. 807-827.

[11] Babinec A., Apeltauer J. On accuracy of position estimation from aerial imagery captured by lowflying UAVs. International Journal of Transportation Science and Technology, vol. 5, issue 3, 2016, pp. 152-166.

[12] Uysal M., Toprak A., Polat N. DEM generation with UAV Photogrammetry and accuracy analysis in Sahitler hill. Measurement, vol. 73, 2015, pp. 539-543.

[13] Tonkin T., Midgley N., Graham D. The potential of small unmanned aircraft systems and structure-from-motion for topographic surveys: A test of emerging integrated approaches at Cwm Idwal, North Wales. Geomorphology, vol. 226, 2014, pp. 35-43.

[14] Pádua L., Adão T., Hruška J. Very high resolution aerial data to support multi-temporal precision agriculture information management. Procedia Computer Science, vol. 121, 2017, pp. 407-414.

[15] Turner I., Harley M., Drummond C. UAVs for coastal surveying. Coastal Engineering, vol. 114, 2016, pp. 19-24.

[16] Ajayi O., Palmer M., Salubi A. Modelling farmland topography for suitable site selection of dam construction using unmanned aerial vehicle (UAV) photogrammetry. Remote Sensing Applications: Society and Environment, vol. 11, 2018, pp. 220-230.

[17] Ruzgienė B., Berteška T., Gečyte S. The surface modelling based on UAV Photogrammetry and qualitative estimation. Measurement, vol. 73, 2015, pp. 619-627.

[18] Colomina I., Molina P. Unmanned aerial systems for photogrammetry and remote sensing: A review. ISPRS Journal of Photogrammetry and Remote Sensing, vol. 92, 2014, pp. 79-97.

[19] Kršák B., Blišt’an P., Pauliková A. Use of low-cost UAV photogrammetry to analyze the accuracy of a digital elevation model in a case study. Measurement, vol. 91, 2016, pp. 276-287. 